\title{
Editorial
}

\section{Mobilizing Evidence for Impact: From CDIC to Health Promotion and Chronic Disease Prevention}

\author{
Kerry Robinson, PhD, Publisher, Health Promotion and Chronic Disease Prevention in Canada \\ Michelle Tracy, MA, Managing Editor, Health Promotion and Chronic Disease Prevention in Canada
}

Tweet this article

The journal Health Promotion and Chronic Disease Prevention in Canada: Research, Policy and Practice (HPCDP) (formerly Chronic Diseases and Injuries in Canada [CDIC]) had humble beginnings at Health Canada in 1980 as a "New Bulletin" aimed at publishing "material based on research, surveillance and control aspects of non-communicable diseases or conditions such as cancer, heart disease and accidents."1 The main audience for this new national publication was the estimated 300 to 400 Canadian professionals involved directly or indirectly in programs related to chronic disease.

Now, 35 years later, with an impact factor of 1.22 , the journal has become a credible source of peer-reviewed scientific research and an important platform for knowledge exchange within Canada's public health community. As an open-access and bilingual journal, it also serves readers in the United States, Europe and francophone Africa. To date, the journal has published hundreds of articles on a range of topics from maternal health to injuries to cancer trends. It has a robust online presence via many scientific publication indexes and aggregators, including MEDLINE, Thomson Reuters, Elsevier, SCOPUS and EBSCO.

Just as the journal's subject matter has expanded over time and we have moved from a small printing press to an online, fully accessible publication, the journal is now evolving its governance and production model. The new governance model is based on existing governance practices for government-published journals, like Statistics Canada's Health Reports or the
AECL (Atomic Energy of Canada Limited) Nuclear Review. As a federal government publication, HPCDP will feature articles that showcase applied science and research on disease prevention, health promotion and health equity in the areas of chronic diseases, injuries and life course health, with a key focus on the Public Health Agency of Canada's research and collaborations. It is important to note, however, that the new model does not represent a change in topic scope for the journal, as CDIC has been publishing in each of these areas for over a decade.

The journal will maintain its high scientific credibility by maintaining central inclusion of external associate scientific editors and peer reviewers, as well as an editorial board primarily composed of members external to the federal government. These external advisors will continue to contribute their expertise to reviewing papers and ensuring that the articles published in HPCDP remain of high quality and expand upon the latest pan-Canadian knowledge in this field.

HPCDP's new model also represents a move from passive knowledge dissemination to a more integrated model involving interactive and collaborative knowledge exchange. Within the realm of knowledge translation, traditional (passive) dissemination approaches often result less successfully in uptake of public health innovations. ${ }^{2}$ It was within this context, and within the context of a transformation of science governance as a whole within the Public Health Agency of Canada (the publisher of this journal), that a new governance and publishing model for the journal was proposed.

In the past, public health has emphasized the creation and publication of applied research; however, there is now a growing need for this knowledge to be better synthesized and translated for use by a range of decision makers., ${ }^{3,4}$ The renewed HPCDP will showcase the breadth and quality of collaborative government science, surveillance and intervention evaluation/studies. The journal represents an important dissemination platform for the Agency's peer-reviewed health promotion and chronic disease prevention science. Our goal is to continue to grow the journal as a much-needed vehicle to share and support use of peer-reviewed public health science/research, analysis and related collaborative work with applied research, policy and practice audiences in Canada.

As part of its aim to increase policy relevant and intervention-related evidence that can help inform policy and practice decisions, HPCDP has expanded its types of articles to include evidence syntheses and evidence briefs, qualitative and mixed methods studies and intervention studies, as well as a section called "At-a-Glance" that allows for quick statistics updates from the latest surveillance analyses [see http://www.phac-aspc.gc.ca/publicat/hpcdp -pspmc/authinfo-eng.php].

HPCDP is also demonstrating its responsiveness to a need for increased mobilization for uptake and impact. While a 2012 
Stakeholder Satisfaction Survey showed that most respondents were satisfied with the journal ( $90 \%$ overall satisfaction), some remarked that using social media to promote journal content would increase awareness of and access to the journal. With this and the demand for quicker access to evidence in view, the journal has now become a monthly, online-only publication, which allows us to accelerate the frequency and timeliness of article release. We will be promoting and sharing published findings through professional social networking sites, webinars and social media platforms and looking into mobile options for the journal.

Going forward, the journal will place greater emphasis on collaborative research and analysis between government and external researchers, a range of public health practitioners, health policy planners and related professionals. As part of this new model, the journal particularly welcomes articles resulting from a substantive collaboration with the Public Health Agency or Health Canada, through co-authorship (including with staff from the Canadian Institutes of Health Research), funding or use of Public Health Agency or Health Canada data.*

In the same collaborative vein, HPCDP is being renewed to also increase access and use of a broader range of public health and community systems knowledge. ${ }^{4}$ The Agency will be in a position to share externally in a more timely fashion the various evidence syntheses and high quality Canadian scans that we conduct in collaboration with others; these are often not published by other means on the web or disseminated broadly.

We are pleased to welcome you to this inaugural issue of the journal's new model. The original research articles "A DASH dietary pattern and the risk of colorectal cancer among Canadian adults,'” by JonesMcLean et al., and "Chronic fatigue syndrome and fibromyalgia in Canada: Prevalence and associations with six health status indicators," by Rusu et al., contribute to the Canadian evidence base in these fields. This issue also features summaries of the Agency's latest surveillance reports on two important areas, perinatal health indicators and congenital anomalies. Finally, please do look at the section "Other PHAC Publications," which highlights and links to peer-reviewed article collaborations published in other venues.

We hope that you enjoy some of the features of our new journal model. On behalf of our colleagues at the Public Health Agency of Canada, we look forward to collaborating with you on the creation, synthesis and mobilization of applied research and analysis for positive impact on health promotion and chronic disease prevention in Canada.

\section{References}

1. Clayton AJ. Guest editorial - Launching of new bulletin. Chronic Dis Can. 1980;1(1):1.

2. Robinson K, Elliott SJ, Driedger SM, et al. Using linking systems to build capacity and enhance dissemination in heart health promotion: a Canadian multiple-case study. Health Educ Res. 2005;20(5):499-513.

3. Speller V, Wimbush E, Morgan A. Evidence-based health promotion practice: how to make it work? Promot Educ. 2005; Suppl 1:15-20.

4. McDonald PW, Viehbeck S. From Evidencebased practice making to practice-based evidence making: creating communities of (research) and practice. Health Promot Pract. $2007 ; 8(2): 140-4$.

\footnotetext{
* PHAC/Health Canada data are defined as those datasets that are owned (solely or collaboratively) by PHAC or Health Canada, or of which PHAC or Health Canada are the custodians or guardians.
} 